\title{
Pengadaan Taman Bermain Anak Untuk Peningkatan Kualitas Pendidikan di Madrasah Ibtidaiyah Nurul Huda II Dusun Gunung Leutik Kabupaten Bogor
}

\author{
Dedi Hantono*1, Ashadi², Ari Widyati Purwantiasning ${ }^{3}$, Anisa $^{4}$, Ratna Dewi Nur'aini5, \\ Yeptadian Sari6 \\ 1,2,3,4,5,6Program Studi Arsitektur, Fakultas Teknik, Universitas Muhammadiyah Jakarta \\ *e-mail: dedihantono@umj.ac.id
}

\begin{abstract}
The most important early childhood development is in its golden period. To maintain their potential, several stimuli can be carried out, including tactile stimuli, in the form of stimuli of motion. Schools as the main means of producing educated children need adequate facilities and infrastructure. Especially for early childhood education, a means of play is needed to carry out the tactile stimulus needed by school students at the elementary level. Based on this, the community service activities hold children's play spaces in public spaces and integrated with reading halls so that they can be accessed easily. The evaluation results show that the playground that has been created can increase educational activities by observing the development of the number of visitors to the reading house.
\end{abstract}

Keywords: playground, public space, children education, golden age, reading interest.

\begin{abstract}
Abstrak
Perkembangan anak usia dini yang terpenting berada pada masa emasnya. Untuk menjaga potensi mereka dapat dilakukan beberapa stimulus diantaranya stimulus taktil yaitu berupa rangsangan gerak. Sekolah sebagai sarana utama dalam menghasilkan anak yang berpendidikan memerlukan sarana dan prasarana yang memadai. Khusus pendidikan anak usia dini, sarana bermain sangat diperlukan untuk melakukan stimulus taktil yang dibutuhkan para siswa sekolah pada level dasar. Atas dasar hal tersebut maka kegiatan pengabdian masyarakat ini mengadakan ruang bermain anak pada ruang publik dan terintegrasi dengan pondok baca agar dapat diakses oleh mereka dengan mudah. Hasil evaluasi menunjukkan bahwa taman bermain yang telah dibuat dapat meningkatkan aktivitas pendidikan dengan melihat perkembangan jumlah pengunjung pondok baca.
\end{abstract}

Kata kunci: taman bermain, ruang publik, pendidikan anak, usia emas, minat baca.

\section{PENDAHULUAN}

Usia anak dini merupakan salah satu periode terpenting dalam pembentukan karakter, kepribadian, dan tingkat kecerdasan seseorang. Perkembangan pada usia ini mempengaruhi kehidupan seseorang pada tahap berikutnya atau yang biasa disebut masa emas (Susilowati, Mujiastuti, Ambo, \& Sugiartowo, 2019) (Filtri, Bastian, \& Reswita, 2017).

Perkembangan potensi seorang anak dapat dilakukan dengan melakukan stimulasi atau rangsangan dari luar (Mutiah, 2015). Adapun stimulasi tersebut ada 3 bentuk, yaitu:

1. Stimulasi visual, yaitu rangsangan terhadap penglihatan, seperti: warna, bentuk, dan lain-lain. Pemilihan warna yang tepat dapat mendukung aktivitas anak dalam mencapai perkembangan yang maksimal (Nur'aini, 2016).

2. Stimulasi verbal, yaitu rangsangan berupa bunyi-bunyian, seperti: musik, suara burung, dan lain-lain.

3. Stimulasi taktil, yaitu rangsangan berupa sentuhan dan gerakan, seperti: sentuhan, aktivitas, dan lain-lain. Biasanya hal ini bisa didapat dengan melakukan aktivitas bermain. Gerak aktif ini sangat penting bagi mereka pada usia pertumbuhan (Masruroh, Mauliani, \& Anisa, 2015).

Sekolah dan guru merupakan sarana utama yang menentukan perkembangan potensi seorang anak sedangkan prasarana merupakan bagian pendukung dari kegiatan tersebut. Guru sebagai aktor utama dalam kegiatan pendidikan juga bergantung terhadap prasarana sekolah yang tersedia, seperti: toilet, kantin, dan khususnya untuk pendidikan anak usia dini adalah ruang bermain anak. Ruang bermain ini sendiri bisa ditempatkan di dalam ruangan atau di luar ruangan. 
Perbedaan yang utama pada kedua letak ruang bermain tersebut adalah ruang bermain yang berada di luar ruangan apalagi di ruang terbuka publik akan lebih mudah diakses oleh masyarakat (Hantono \& Pramitasari, 2018).

Potret sekolah yang ideal sepertinya tidak dimiliki oleh Madarasah Ibtidyah Nurul Huda II Dusun Gunung Leutik. Sekolah setara sekolah dasar ini merupakan satu-satunya yang dimiliki oleh dusun ini dengan kondisi fisik yang cukup memprihatinkan. Jika daya tampung sudah tidak tercukupi atau bila ingin melanjutkan sekolah maka harus memilih sekolah di dusun atau desa lain yang jaraknya lumayan jauh dan tidak dilewati oleh transportasi umum. Padahal dusun ini didominasi oleh kaum perempuan dan anak-anak sehingga sangat membutuhkan sarana pendidikan yang memadai. Kondisi ini semakin memprihatinkan dengan tidak adanya sarana bermain anak-anak sebagai karakteristik usia anak-anak yang selalu aktif bermain.

Selama ini para siswa memanfaatkan waktu bermain diantara jam pelajaran sekolah dengan berlari-lari di lapangan sepak bola yang berada di depan sekolah. Aktivitas bermain ini tetap dilakukan oleh para siswa walau lapangan tersebut sedang digunakan untuk bertanding atau berlatih sehingga dapat membahayakan para siswa. Selain lapangan sepak bola, mereka juga bermain di tebing belakang sekolah yang juga cukup membahayakan keselamatan mereka.

Melihat potensi dusun yang didominasi oleh anak-anak dengan permasalahan sarana pendidikan yang jauh dari memadai serta kompetensi keilmuan prodi arsitektur maka kegiatan ini bermaksud melengkapi sarana sekolah dengan ruang untuk bermain anak yang bertujuan untuk ikut serta meningkatkan kualitas pendidikan di Madarasah Ibtidyah Nurul Huda II pada dusun tersebut.

\section{METODE PELAKSANAAN KEGIATAN} ini:

Pelaksanaan kegiatan pengabdian masyarakat ini dilakukan melalui tahap-tahap berikut

a. Pembentukan Tim, kegiatan yang dilaksanakan oleh Program Studi Arsitektur Universitas Muhammadiyah Jakarta (PSA-UMJ) ini sepenuhnya dibentuk oleh tim yang beranggotakan oleh para dosen dan dekan fakultas teknik sebagai pembina.

b. Perumusan Tujuan, kegiatan pengabdian ini sepenuhnya untuk memenuhi kebutuhan masyarakat Dusun Gunung Leutik Desa Kiarasari Kabupaten Bogor yang berorientasi kepada masalah ke-ruang-an. Aspek ini dipilih karena program studi arsitektur merupakan institusi pendidikan dengan kompetensi ilmu dalam bidang lingkungan binaan.

c. Identifikasi Stakeholder, setiap tempat memiliki karakteristik wilayahnya masing-masing termasuk Dusun Gunung Leutik yang terletak di bawah kaki Gunung Halimun. Oleh karena itu diperlukan identifikasi permasalahan dengan mengirim beberapa dosen untuk melakukan survei lokasi.

d. Analisa Kebutuhan, data yang dibawa dari lokasi kegiatan menjadi bahan analisa kebutuhan yang diperlukan oleh penduduk setempat. Untuk memilih beberapa permasalahan yang didapat dari identifikasi stakeholder maka aspek ke-ruang-an digunakan sebagai filter kebutuhan yang akan dipilih dalam kegiatan pengabdian masyarakat ini. Program studi juga mengundang salah satu tokoh masyarakat untuk menyampaikan maksud kegiatan yang akan dilakukan dan menyamakan persepsi kebutuhan dengan stakeholder.

e. Persiapan, sebelum keberangkatan dalam melaksanakan kegiatan pengabdian masyarakat dilakukan beberapa persiapan agar pelaksanaan kegiatan pengabdian masyarakat ini berjalan dengan lancar dan sesuai dengan tujuan

f. Implementasi, penentuan metode pelaksanaan ini diperlukan agar kegiatan pengabdian masyarakat ini berjalan dengan baik dan sesuai dengan tujuan. 
g. Evaluasi, oleh karena waktu kegiatan yang terbatas untuk pelaporan dan pertanggungjawaban kepada pihak BKKBN sebagai penyandang dana maka evaluasi kegiatan hanya dalam waktu 1 (satu) bulan dari waktu pelaksanaan kegiatan.

h. Kesimpulan, diperlukan sebagai bahan rujukan untuk kegiatan pengabdian masyarakat selanjutnya.

\section{HASIL DAN PEMBAHASAN}

Empat bulan sebelum waktu pelaksanaan telah ditentukan tim dosen yang akan mengikuti kegiatan pengabdian masyarakat ini. Oleh karena kegiatan ini membutuhkan dana yang cukup besar akhirnya program studi mencari mitra dari institusi lain untuk mendapatkan dana sesuai dengan anggaran yang telah ditentukan. Badan Kependudukan dan Keluarga Berencana Nasional (BKKBN) Pusat yang salah satu core business-nya adalah meningkatkan kesejahteraan penduduk terutama bagi para ibu dan anak akhirnya bersedia menjalin kerja sama dalam kegiatan Pengabdian Masyarakat Program Studi Arsitektur Universitas Muhammadiyah Jakarta di Dusun Gunung Leutik Desa Kiarasari Kabupaten Bogor.

Sasaran utama kegiatan pengabdian masyarakat adalah ruang terbuka publik pada kawasan permukiman dalam hal ini Dusun Gunung Leutik. Hal ini dilatarbelakangi aktivitas masyarakat desa yang cenderung banyak dilakukan di luar rumah mulai dari bekerja hingga bersosialisasi dengan sesama warganya. Pemahaman ini sejalan dengan Hantono (2019) bahwa banyak aktivitas yang dilakukan di ruang terbuka publik karena kebebasan akses dan waktu. Corak aktivitas tersebut banyak dipengaruhi oleh kondisi sosio-budaya penduduk setempat (Hantono, 2019). Konsep ini kemudian didiskusikan dengan BKKBN dan mendapat kesepakatan bersama bahwa kegiatan pengabdian masyarakat difokuskan pada ruang terbuka publik di Dusun Gunung Leutik dengan korelasinya peningkatan kesejahteraan penduduk terutama ibu dan anak.

Satu bulan menjelang kegiatan program studi mengirim 2 dosen beserta 1 staf administrasi untuk melakukan survei lokasi sekaligus mengidentifikasi permasalahan dan kebutuhan masyarakat setempat yang diwakili oleh salah satu tokoh masyarakat, yaitu Pak Adi. Hasil identifikasi lapangan berdasarkan peninjauan langsung dan keinginan masyarakat terdapat beberapa kebutuhan, diantaranya:

a. Pengadaan air bersih, selama ini masyarakat sangat bergantung dengan sumber mata air yang bisa habis ketika musim kemarau tiba sehingga diperlukan sistem pengadaan air bersih yang berkelanjutan.

b. Pengadaan MCK, masyarakat banyak menggunakan kondisi alam untuk melakukan kegiatan MCK sehingga bisa merusak lingkungan hidup dusun mereka.

c. Pengadaan listrik, masyarakat sangat mengandalkan mesin generator sebagai penerangan kampung pada saat malam hari yang memerlukan biaya yang cukup besar dengan kapasitas terbatas.

d. Sarana dan prasarana sekolah, Madrasah Ibtidaiyah Nurul Huda II merupakan satu-satunya sekolah di dusun tersebut. Kondisi fisik sekolah ini cukup memprihatinkan dengan perlengakapan pendukung yang terbatas diantaranya ruang bermain bagi anak-anak pada usia mereka.

Hasil identifikasi tersebut kemudian dianalisa oleh tim PSA-UMJ dengan BKKBN agar mendapatkan kesamaan visi dan penyesuain anggaran. Pada akhirnya dipilih program pengadaan ruang bermain untuk anak dengan beberapa pertimbangan, diantaranya:

a. Sesuai tujuan awal PSA-UMJ untuk fokus pada ruang terbuka publik.

b. Adanya kesamaan program kegiatan dari BKKBN yaitu Kampung KB dimana salah satu kegiatan dari program tersebut adalah peningkatan kualitas ruang bersama warga. 
c. Kesesuaian anggaran yang disediakan oleh BKKBN.

Untuk mensosialisasikan kegiatan ini PSA-UMJ mengundang tokoh masyarakat dari Dusun Gunung Leutik yang diwakili oleh Pak Adi sebagai salah satu tokoh masyarakat dusun tersebut. Dari kegiatan kunjungan ini disepakati kegiatan yang akan dilaksanakan berupa pengadaan taman bermain anak sekaligus penetapan lokasi taman bermain berdasarkan pengajuan dari Pak Adi dan pertimbangan terhadap tujuan kegiatan ini.

Lokasi taman bermain yang dipilih adalah lahan kosong yang berada di depan sekolah dan berada satu lokasi dengan pondok baca sehingga diharapkan dengan adanya lokasi yang terintegrasi seperti ini memberi peningkatan nilai pada masing-masing fungsi ruang tersebut (Hakim, 2016). Tujuan lain menggabungkan taman bermain dan pondok baca ini adalah menjadikan keiatan mebaca sebagai wisata ilmu pengetahuan yang ditanamkan sejak dini tanpa adanya rasa paksaan (Basalamah, Rizal, \& Efendi, 2020). Pada jangka waktu panjang, ruang terbuka yang dimanfaatkan sebagai pusat aktivitas anak-anak dapat dijadikan pusat mitigasi bagi penduduk setempat sehingga diharapkan lebih memudahkan para orang tua mencari dan mengumpulkan anak-anak pada saat terjadi gempa atau bencana alam lainnya (Prihatiningrum, Ramawangsa, Bahri, \& Yundrismein, 2018).

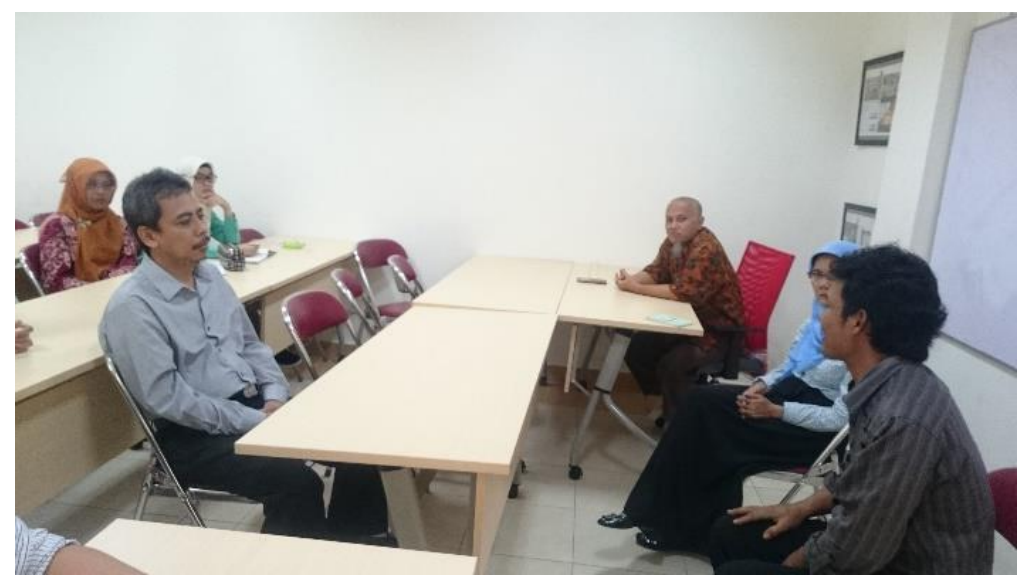

Gambar 1. Mengundang salah satu tokoh masyarakat di PSA-UMJ

Pengadaan peralatan bermain anak outdoor berasal dari Jakarta yang kebetulan lokasinya tidak jauh dari PSA-UMJ. Peralatan tersebut dikirim langsung oleh penjual ke lokasi seminggu sebelum kegiatan pengabdian masyarakat dilakukan.

Pada hari pelaksanaan kegiatan pengabdian masyarakat diikuti oleh 6 dosen dan 1 staf administrasi PSA-UMJ serta perwakilan BKKBN yaitu dr. Noer Aziza. Peserta dari PSA-UMJ dan BKKBN disambut oleh beberapa orang tokoh masyarakat setempat diantaranya: Pak Adi, perwakilan pegawai Kantor Desa Kiarasari, dan guru-guru di salah satu ruang kelas Madrasah Ibtidaiyah Nurul Huda II. Setelah melakukan ramah tamah maka dan saling tukar tanda cendera mata maka seluruh peserta kegiatan ini menuju ke lokasi taman bermain yang ditentukan. Pada kesempatan ini PSA-UMJ dan BKKBN melakukan pemasangan alat bermain secara simbolis. 


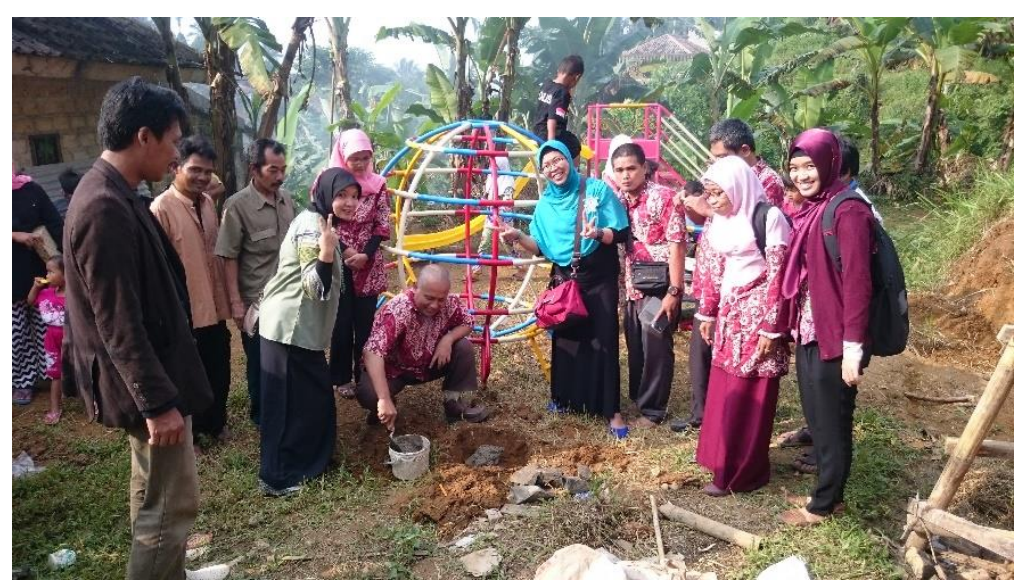

Gambar 2. Pemasangan alat bermain secara simbolik

Untuk melihat keberhasilan dari kegiatan ini dilakukan evaluasi. Adapun waktu yang ditetapkan oleh BKKBN hanya dalam waktu 1 bulan karena keperluan mereka untuk melaporkan kembali ke bagian anggaran kantor. Oleh karena keterbatasan waktu dan lokasi kegiatan yang sangat jauh dan sulit dijangkau maka data yang didapat oleh PSA-UMJ berasal dari laporan Pak Adi melalui hubungan telepon dan pesan singkat per minggu.

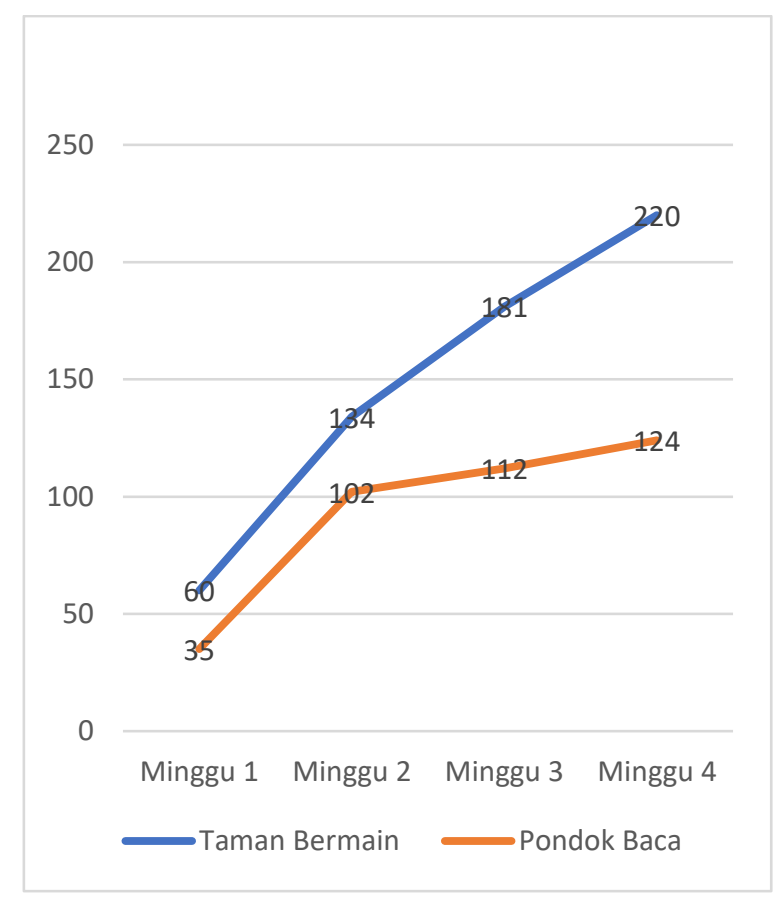

Gambar 3. Pengguna taman bermain dan pondok baca perminggu

Dari gambar data di atas tergambar bahwa jumlah pengunjung taman bermain dan pondok baca terus mengalami kenaikan setiap minggunya. Namun kenaikan pengunjung pondok baca tidak setajam dan selalu berada di bawah grafik pengunjung taman bermain. Jika dilihat gambar rangkaian garis statistik pengunjung pondok baca cenderung mengalami kelandaian diakhir bulan. Untuk itu sebenarnya masih diperlukan evaluasi lanjutan apakah pergerakan garis tersebut masih terus cenderung landau atau bahkan menurun sehingga perlu dilakukan penelitian lebih lanjut. 


\section{KESIMPULAN}

Pengadaan ruang bermain sebagai stimulasi aktivitas anak usia dini sangat diminati oleh para siswa. Bukan hanya itu, lokasinya yang berada pada satu area dengan pondok baca ikut meningkatkan minat membaca bagi siswa di pondok baca walaupun keniakna tersebut tidak begitu signifikan dibanding kenaikan pengunjung taman bermain.

Angka statistik tersebut menunjukkan bahwa dengan pengadaan taman bermain membawa pengaruh terhadap minat membaca para siswa pada skala waktu pendek. Untuk mengetahui dampak lainnya perlu dilakukan evaluasi dan penelitian lebih lanjut dalam rentang waktu yang cukup panjang.

\section{UCAPAN TERIMA KASIH}

Pada kesempatan ini Penulis mengucapkan terima kasih kepada Badan Kependudukan dan Keluarga Berencana Nasional (BKKBN) Direktorat Advokasi dan KIE dalam hal ini diwakili oleh dr. Noer Aziza yang turut membantu terlaksananya kegiatan Pengabdian Masyarakat Program Studi Arsitektur Universitas Muhammadiyah Jakarta terutama dukungan materil berupa bantuan dana sepenuhnya untuk pengadaan Taman Bermain Anak di Sekolah Madrasah Ibtidyah Nurul Huda II Dusun Gunung Leutik Desa Kiarasari Kabupaten Bogor.

\section{DAFTAR PUSTAKA}

Basalamah, M. R., Rizal, M., \& Efendi, E. (2020). Penyediaan Rumah Baca Masyarakat Sebagai Solusi Cerdas Mengawali Budaya Membaca. Dinamisia: Jurnal Pengabdian Kepada Masyarakat, 4(1), 36-42. https://doi.org/10.31849/dinamisia.v4i1.3756

Filtri, E., Bastian, A., \& Reswita. (2017). Peran Komunikasi Orangtua dengan Guru Dalam Pembentukan Karakter Anak Usia Dini. Dinamisia, 1(1), 1-4. https://doi.org/10.31849/dinamisia.v1i1.128

Hakim, A. H. (2016). Integrasi di Kawasan Strategis Cagar Budaya Benteng Malborough, Bengkulu. Tekno Global, 5(1), 27-32. https://doi.org/10.36982/jtg.v5i1.93

Hantono, D. (2019). Kajian Perilaku Pada Ruang Terbuka Publik. Nalars, 18(1), 45-56. https://doi.org/10.24853/nalars.18.1.45-56

Hantono, D., \& Pramitasari, D. (2018). Aspek Perilaku Manusia Sebagai Makhluk Individu dan Sosial pada Ruang Terbuka Publik. Nature, 5(2), 59-67. https://doi.org/10.24252/nature.v5i2a1

Masruroh, F., Mauliani, L., \& Anisa. (2015). Kajian Arsitektural Taman yang Mengakomodasi Aksesibilitas Difabel Studi Kasus Taman Tribeca Central Park Mall, Taman Menteng dan Taman Ayodia. NALARS, 14(2), 145-167. https://doi.org/10.24853/nalars.14.2.\%25p

Mutiah, D. (2015). Psikologi Bermain Anak Usia Dini (Pertama). Jakarta: Kencana.

Nur'aini, R. D. (2016). Kajian Penggunaan Warna pada Interior Ruang Pembelajaran Anak Usia Dini. Rekayasa, 6(1), 1-8.

Prihatiningrum, A., Ramawangsa, P. A., Bahri, S., \& Yundrismein, R. (2018). Konfigurasi Massa Bangunan dalam Upaya Mitigasi Bencana pada Kawasan Pusaka Kota Bengkulu. In Seminar Nasional Inovasi, Teknologi dan Aplikasi (SeNITiA) (pp. 243-247). Bengkulu: Fakultas Teknik Universitas Bengkulu. Retrieved from http://senitia.ft.unib.ac.id/prosiding/2018f-1-43atik-prihatiningrum/

Susilowati, E., Mujiastuti, R., Ambo, S. N., \& Sugiartowo. (2019). Stimulasi, Deteksi dan Intervensi Dini Tumbuh Kembang (SDIDTK) Anak pada Pos Yandu Kelurahan Penggilingan Jakarta Timur. Jurnal Pengabdian Masyarakat Teknik (JPMT), 1(2), 59-68. 